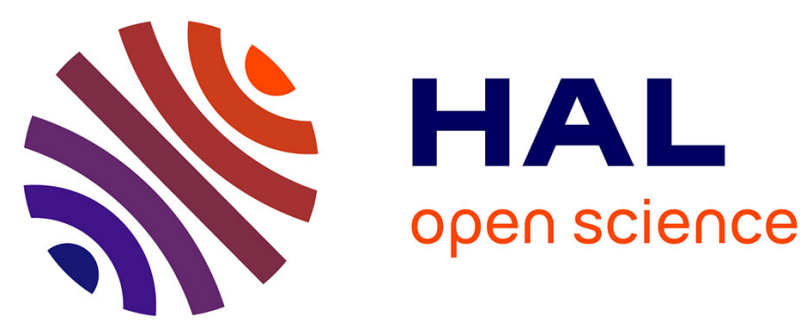

\title{
Is universal prevention against youths' substance misuse really universal? Gender specific effects in the EU-Dap school-based prevention trial.
}

Federica Vigna-Taglianti, Serena Vadrucci, Fabrizio Faggiano, Gregor

Burkhart, Roberta Siliquini, Maria Rosaria Galanti, The Eu-Dap Study Group

\section{To cite this version:}

Federica Vigna-Taglianti, Serena Vadrucci, Fabrizio Faggiano, Gregor Burkhart, Roberta Siliquini, et al.. Is universal prevention against youths' substance misuse really universal? Gender specific effects in the EU-Dap school-based prevention trial.. Journal of Epidemiology and Community Health, 2009, 63 (9), pp.722-n/a. 10.1136/jech.2008.081513 . hal-00477878

\section{HAL Id: hal-00477878 \\ https://hal.science/hal-00477878}

Submitted on 30 Apr 2010

HAL is a multi-disciplinary open access archive for the deposit and dissemination of scientific research documents, whether they are published or not. The documents may come from teaching and research institutions in France or abroad, or from public or private research centers.
L'archive ouverte pluridisciplinaire HAL, est destinée au dépôt et à la diffusion de documents scientifiques de niveau recherche, publiés ou non, émanant des établissements d'enseignement et de recherche français ou étrangers, des laboratoires publics ou privés. 
Title

Is universal prevention against youths' substance misuse really universal? Gender specific effects in the EU-Dap school-based prevention trial.

\title{
Running title
}

Gender specific effects in the EU-Dap school-based prevention trial.

\section{Authors}

Federica Vigna-Taglianti ${ }^{1,2}$, Serena Vadrucci $^{1}$, Fabrizio Faggiano ${ }^{1,2}$, Gregor Burkhart $^{3}$, Roberta Siliquini ${ }^{4}$, Maria Rosaria Galanti ${ }^{5,6}$ and the EU-Dap Study Group ${ }^{a}$

${ }^{1}$ Piedmont Centre for Drug Addiction Epidemiology, ASLTO3, Grugliasco (TO), Italy

${ }^{2}$ Department of Clinical and Experimental Medicine, Avogadro University, Novara, Italy

${ }^{3}$ EMCDDA, European Monitoring Centre for Drugs and Drug Addiction, Lisboa, Portugal

${ }^{4}$ Department of Public Health, University of Turin, Italy

${ }^{5}$ Stockholm Centre for Public Health/Tobacco Prevention, Stockholm County Council, Sweden

${ }^{6}$ Department of Medicine Solna, Clinical Epidemiology Unit, Karolinska Institutet, Sweden

\begin{abstract}
${ }^{a}$ The EU-Dap Study Group includes (beside the authors): Barbara Zunino, Valeria Siliquini, GLuca Cuomo, Laura Vitale (Piedmont Centre for Drug Addiction Epidemiology, Turin, Italy); Karl Bohrn (Institut für Sozial und Gesundheitspsychologie, Wien, Austria), Peer van der Kreeft, Erwin Coppens, Yannick Weyts (De Sleutel, Merelbeke, Belgium); Juan Carlos Melero, Tatiana Perez, Laura Varona (EDEX, Bilbao, Spain); Gudrun Wiborg (IFT-Nord, Kiel, Germany); Vicky Yotsidi, Clive Richardson (University Mental Health Research Institute, Athens, Greece); Maro Vasara, Maria Kyriakidou (Pyxida, Thessaloniki, Greece); AnnMarie Lindahl (Stockholm Centre of Public Health and Dept of Public Health Sciences, Karolinska Institutet, Sweden); Massimiliano Panella (Dept of Clinical and Experimental Medicine, Avogadro University, Novara, Italy); Leila Fabiani, Maria Scatigna (Dept of Internal Medicine and Public Health, University of L'Aquila).
\end{abstract}

\section{Corresponding Author}

Federica Vigna-Taglianti

Piedmont Centre for Drug Addiction Epidemiology, ASLTO3

Via Sabaudia 164, 10095 Grugliasco (Torino), Italy

Phone: 0039-011-40188305

Fax: 0039-011-40188301

Email address: federica.vignataglianti@oed.piemonte.it

Word count: 3359

\section{$\underline{\text { Keywords }}$}

school-based prevention, comprehensive social influence model, effectiveness, substance use, gender differences. 


\section{$\underline{\text { Licence statement }}$}

"The Corresponding Author has the right to grant on behalf of all authors and does grant on behalf of all authors, an exclusive licence (or non exclusive for government employees) on a worldwide basis to the BMJ Publishing Group Ltd and its Licensees to permit this article (if accepted) to be published in JECH editions and any other BMJPGL products to exploit all subsidiary rights, as set out in our licence (http://jech.bmj.com/ifora/licence.pdf)". 


\section{Abstract}

Background. Studies of effectiveness of school-based prevention of substance misuse have generally overlooked gender differences. The purpose of this work was to analyse gender differences in the effectiveness of a new European school-based curriculum for prevention of substance misuse among adolescents.

Methods. The EU-Dap trial took place in seven European countries during the school year 2004-05. Schools were randomly assigned to either a control group or a 12-sessions standardized curriculum ("Unplugged") based on a comprehensive social influence model. The study sample at baseline consisted of 7079 students (3324 boys and 3035 girls). The use of cigarettes, alcohol, and illicit drugs, adolescents' knowledge and opinions about substances, as well as social and personal skills were investigated through a selfcompleted anonymous questionnaire administered at enrolment and three months after the end of the program. Adjusted Prevalence Odds Ratios were calculated as measure of association between the intervention and behavioural outcomes using multilevel regression modelling.

Results. At enrolment, boys were more likely than girls to have used cannabis and illicit drugs, while girls had a higher prevalence of cigarette smoking. At post-test, a significant association between program and lower prevalence of all behavioural outcomes was found among boys, but not among girls. Age and self-esteem emerged as possible modifiers of these gender differences, but effects were not statistically significant.

Conclusions. Comprehensive social influence school curricula against substance misuse in adolescence may perform differently among girls and boys, due to developmental and personality factors. 


\section{Introduction}

There are well known gender differences in substance use, including age of start, pattern of use, risk factors, access to treatment, and even treatment effectiveness. [1, 2]

Concerning primary prevention, few studies have systematically investigated gender differences in the effectiveness of interventions.[3] When differences have been found, the general evidence seems in favour of a higher effectiveness among girls.[3] However, limiting the evidence to school-based interventions, the findings appear rather mixed. For example, project SMART was effective on females but virtually had no effect on males [4], such as ALERT Plus.[5] On the contrary, keepin'it REAL program showed more beneficial effects on alcohol and cigarette use, and anti-drug norms among the boys.[6] The Oslo Youth Study showed effects only among baseline non-smoking males and no treatment effects at all for females.[7] In the North Karelia Youth Programme the effect on tobacco consumption was slightly more pronounced among males than among females.[8] Project Towards No Drug Abuse was effective in preventing marijuana use among males nonusers.[9] DARE and DARE Plus Programmes were effective on tobacco, alcohol and polydrug use among boys and not effective at all among girls.[10] Three out of five of the programs effective on males were based on the social influence approach (Oslo Youth Study, North Karelia Youth Programme, Project Towards No Drug Abuse), as well as Project SMART and ALERT Plus, more effective among girls.

One reason behind the inconsistent results achieved in the evaluation of programs effects may be that effectiveness is not homogeneous across subgroups of the target population. For instance, some prevention studies found that the program efficacy was higher among baseline users.[11,5] Such differences could be related to program delivery or to personal characteristics of the pupils (e.g. age, stage of use, development). Given the inconsistent results observed in the literature, gender differences become an important issue in all intervention studies. In fact, if a sensitive subgroup exists, this is not only important to guide the program's application, but it may also cast light on the mechanisms of the program effect.

The objective of this work was to analyse gender differences in the effectiveness of a new European school-based curriculum developed and assessed in the EU-Dap trial, and to analyse possible explanations for observed differences. The EU-Dap (European Drug Abuse Prevention) trial is a European multicentric study comparing a comprehensive social influence school curriculum against substance use with traditional programs in use in local schools. Results of the overall effectiveness of the program in reducing the 
probability of use of cigarettes, cannabis and illicit drugs, as well as of recent drunkenness episodes are published elsewhere.[12]

\section{Methods}

\section{Study design and study population}

The study design and the study population of the EU-Dap trial have been described in detail elsewhere [13] and will only be summarized here. The trial took place simultaneously in seven European countries during the school year 2004-2005. Schools were selected on the basis of inclusion criteria and of willingness to cooperate, and randomly assigned to either intervention (102 schools) or control group (68 schools). Of these schools, 77 intervention schools and 64 control schools continued participation throughout the study. A questionnaire investigating substance use and personal and social skills together with other individual and family characteristics was administered at the beginning of the school year (October 2004) and approximately 3 months after the end of the program (May 2005). The intervention took place during the school year and consisted in a 12-sessions standardized curriculum (denominated "Unplugged" in the English version) based on a comprehensive social influence model.[14] The program was taught using interactive techniques and focused on developing and enhancing interpersonal skills (group dynamics, assertiveness, problem solving, creative thinking and self control), and intrapersonal skills (verbal and nonverbal communication, expression of negative feelings, coping skills). Sessions on normative education and information on effects of smoking and drug use were also provided. In one third of the intervention schools the curriculum was complemented with a series of three seminars dedicated to the parents of the students while, in an additional third, two students from each class conducted a "peer-based" intervention in support of the curriculum taught by one of the class teachers. For the purpose of this analysis, all intervention arms were collapsed together (intervention group) and compared to the control group.

The study sample at baseline consisted of 7079 students (3532 in control schools and 3547 in intervention schools). The study sample at the 3-months post-test follow-up consisted of 6370 students who participated at both the baseline and the follow-up survey. Of these students, 11 did not report their sex, leaving an analytical sample of 3324 $(52.2 \%)$ males and 3035 females (47.8\%). The proportion retained at follow-up was $90.3 \%$ among boys and $92.3 \%$ among girls $(p=0.003)$. 


\section{Information on substance use and other covariates}

Information on substance use was obtained by means of a self-completed questionnaire, administered anonymously in the classroom. Substance use was investigated both as use ever in life and as use in the past 30 days. Concerning alcohol drinking, the number of episodes of drunkenness in the past 30 days was chosen as the outcome of interest in this analysis, rather than indicators of average alcohol consumption, because it appears to be a stronger predictor of subsequent escalation of use.[15]

A question aiming to assess self-esteem, encompassing 10 items with response alternatives on a 4-points Likert scale (strongly agree/agree/disagree/strongly disagree) resulted in two different subscales (positive and negative). Since the internal reliability of the positive scale (Cronbach $\alpha=0.69$ ) was higher than the reliability of the negative scale (Cronbach $\alpha=0.64$ ) only the former was used in this analysis. The positive self-esteem subscale was composed of the following 5 items: "I feel I have a number of good qualities"; "I am able to do things as well as most other people"; "I am quite good at sports"; "My being happy is important to my parents"; and "I have plenty of interests and hobbies". Agreement was defined as an answer of "strongly agree/agree" on a 4-points Likert scale. For the purpose of this analysis the total score on the scale was dichotomized as low selfesteem (score 0-3) and high self-esteem (score 4-5).

Positive expectations towards substances were investigated through the answers to the question whether one would expect to: a) feel more relaxed; b) become more popular using tobacco, alcohol, cannabis or other illicit drugs. The question was asked to all pupils, independently on their substance use. Answering agree/definitely agree to the relaxation item was used as indicator of positive expectancy towards the rewarding properties of the substance itself, while the corresponding answer to the popularity item was used as indicator of positive expectancy towards the social effects of substance use.

The age of the students was calculated based on year of birth.

\section{Statistical methods}

From the information on substance use, eight non mutually exclusive outcome variables were derived, all of them with reference to the 30 days preceding the survey: i) any cigarette smoking, defined as smoking at least one cigarette in the past 30 days; ii) frequent cigarette smoking, defined as smoking six or more cigarettes in the past 30 days; iii) daily cigarette smoking, defined as smoking 20 or more cigarettes in the past 30 days; iv) any episode of drunkenness, defined as at least one episode in the past 30 days; v) 
frequent drunkenness, defined as three or more episodes in the past 30 days; vi) any cannabis use, defined as use at least once in the last 30 days; vii) frequent cannabis use, defined as use on three or more occasions in the past 30 days; viii) any illicit drug use, defined as use of any illicit drug (including cannabis) in the past 30 days. All outcome variables were analyzed as dichotomous (yes/no).

Prevalence Odds Ratios (POR) and their corresponding Confidence Intervals (95\% Cl) were calculated as measure of association between experimental conditions (all intervention arms pooled together) and behavioural outcomes, separately by gender.

In order to take into account the hierarchical structure of the data and the cluster effect, a multilevel modelling approach was followed in the analysis of the data.[16] Data were analyzed with MLwiN 2.02 software.[17] Restricted Iterative Generalized Least Square (RIGLS) estimation procedure was used to estimate the random parameters, since it is considered to lead to unbiased estimates.[18] Marginal Quasi Likelihood (MQL) and 'first order' were then selected to include estimated residuals in the RIGLS procedure, and to control the degree of approximation. Multivariate multilevel models were fitted using three grouping levels: centre, class and students. The use of class as group level instead of school, the unit of randomisation, is justified by the larger amount of intraclass correlation coefficient at the level of class than at the level of school.[19] Differences in prevalence of use between centres were adjusted for by including in the model the baseline centre prevalence of current daily smoking, defined as smoking 20 or more cigarettes in the last 30 days. Finally, all estimates were adjusted by individual baseline behaviour of the corresponding outcome.

We also conducted a tabular analysis comparing intervention and control group, separately by gender, as regards to the proportion of students who at the end of follow-up had transitioned to higher (progression) or lower (regression) frequency of use or tobacco, alcohol, and drugs. In order to track these transitions, the following mutually exclusive categories of use were employed: a) non smoker (no cigarette smoking in the past 30 days); b) occasional smoker (1-19 cigarettes in the past 30 days); c) daily smoker (20 or more cigarettes in the past 30 days); d) no drunkenness (no episodes of drunkenness from alcohol drinking in the past 30 days); e) drunkenness (one or more episodes of drunkenness in the past 30 days); f) no cannabis use (no cannabis use in the past 30 days); g) cannabis use (use of cannabis in one or more occasions in the past 30 days). Thus, a case of progression was considered every time a student reported at follow up a more frequent use than at baseline, while a report of less frequent use was considered as 
regression. Students who fell in the same category of use at baseline and at follow-up were considered as staying stable in that stage of use.

\section{Results}

The characteristics of the analytical sample at baseline are shown in Table 1, separately by gender and experimental condition. The age structure did not differ between genders. At enrolment, boys were more likely than girls to have used cannabis $(4.2 \%$ vs $2.4 \%$, $\mathrm{p}<0.001)$ and illicit drugs $(5.6 \%$ vs $4.1 \%, \mathrm{p}=0.005)$ at least once in the past 30 days, while girls had a higher prevalence of any cigarette smoking in the past 30 days $(15.9 \%$ vs $12.7 \%, p<0.001)$. The proportion reporting recent episodes of drunkenness was slightly higher among males, but the difference was not statistically significant $(p=0.07)$. Also, at baseline more boys in the control group were current users of all substances than boys in the intervention group, while this imbalance was not seen among girls.

At baseline, a lower proportion of girls scored high on the positive self-esteem score (83.2\% vs $87.7 \%, p<0.001)$. On the other hand, no appreciable gender differences were seen concerning positive expectations towards smoking, while boys endorsed more often than girls positive expectations towards alcohol ("feel relaxed": $21.2 \%$ vs $18.5 \%, p=0.008$, "become more popular": $17.3 \%$ vs $14.7 \%, p=0.005$ ) and cannabis ("feel relaxed": $41.8 \%$ vs $37.5 \%, p=0.001$, "become more popular": $21.4 \%$ vs $18.6 \%, p=0.006$ ).

\section{$<$ Table 1 here >}

On the follow-up survey conducted three months after the completion of the experimental school curriculum, significant program effects with decreased risks in almost all indicators of substance use were observed among boys (Table 2). Among girls, there was an indication of decreased risk of frequent drunkenness in the past 30 days, but the estimate did not attain the statistical significance.

\section{$<<$ Table 2 here $>$}

This gender difference was also found in centres where significant program effects could be detected on the whole sample, and was maintained even after exclusion of current users at baseline (not shown).

Some gender differences were found concerning the transitions between different stages of substance use from baseline to follow-up. Among boys, the proportion progressing to more advanced stages of smoking was lower among those who received the experimental 
curriculum compared to controls, while the proportion regressing was higher (Table 3). Among girls a similar but less pronounced pattern was observed (Table 4). Daily smokers were not affected by the intervention in either gender, but among girls a higher proportion of the control group regressed from daily use, compared to the intervention group. Similar patterns emerged in the use of other substances: delayed progression and enhanced regression were higher in the intervention group among boys, while no, minimal or reverse differences were observed among girls.

\section{$<<$ Table 3 here>>}

\section{$<<$ Table 4 here $>$}

When the gender-specific estimates of program effect were analysed in separate strata of the self-esteem indicator, some differences emerged (Table 5) although based on not statistically significant estimates. Among boys, level of self-esteem did not substantially affect the curriculum effect seen in the whole group. Among girls, the program was rather associated to a tendency towards unfavourable effect in the group categorized as having low self-esteem (Table 5).

When stratifying the program effects by gender and positive expectancies indicators ("feel more relaxed" and "become more popular", respectively), the results closely matched the main results (data not shown).

\section{$<$ Table 5 here $>>$}

In a separate analysis by gender and age group (Table 6), non statistically significant associations with risk reduction for the exposed to the experimental curriculum compared to controls were found for frequent and daily smoking, as well as for recent drunkenness, among girls in the youngest age group (11-12 years at baseline), while among boys the associations were similar in both age groups.

$<<$ Table 6 here $>$

\section{Discussion}

In a multi-national sample of European students we found pronounced gender differences in the effectiveness of a comprehensive social influence school-based program for the prevention of substance misuse. These differences indicated a greater preventive potential of the curriculum among boys, consistent across diverse geographical locations, 
suggesting that cultural and normative differences can unlikely account for this observation.

This finding was somewhat unexpected, since the new generations of programs based on the enhancement of social skills are generally considered more effective, if anything, among girls than among boys.[3] However, if only school-based social influence interventions are considered, the evidence is rather mixed.

Because the class composition in the schools enrolled for the EU-DAP trial was universally gender balanced, we can exclude program-delivery factors (e.g. that the curriculum was taught differently among boys and among girls). Therefore, the only possible explanations pertains to factors inherent to the receivers.

First, girls may have been reached at more advanced stages of substance use. In a previous report we observed that the program's efficacy was highest in hindering the progression from low- or no use to advanced use.[12] However, females were slightly more advanced than males only in cigarette smoking when recruited for this study, while the differential effectiveness was observed for all classes of substances.

Second, the developmental stage of the two genders in terms of general life skills and coping mechanisms may differ, given attained age.[20, 21] At the same age the acquisition of skills and competences may still be susceptible to modifications among boys, less so among girls. In fact, females must cope with puberty-related social and emotional changes at an earlier age.[21] Consistently, we found indications that the program may have been effective among very young girls (11-12 years old), while the effectiveness among boys did not differ by attained age. Although caution is needed when interpreting these results, due to lack of statistical significance, previous studies support the conclusion that most programs based on skill enhancement achieve better results among girls when administered at young ages. [3, 22]

Third, boys and girls may differ in mediators of programs' effects, such as personality characteristics and expectations towards substances. In our study, positive expectations towards substances did not significantly modify the program's effect in either gender. This was also the case for an indicator of self-esteem, although the data in this case suggested a differential modifying effect of self-esteem on program's effectiveness in the two genders, indicating that girls with low self-esteem had the least benefit from the program.

A differential gender effect linked to self-esteem would not be surprising, and should be thoroughly investigated in larger studies. In fact, there is some evidence that lack of self- 
esteem can be a stronger risk factor for drug use among girls than among boys.[23, 20] Theoretical models [24] suggest that girls are more influenced by family protective factors, while boys are more influenced by school or community environment. Among girls, selfesteem is strongly dependent on a positive relationship with parents.[22]

The emphasis on self-esteem is justified by the fact that this is not a key element of social influence programs, that focus on normative beliefs and on social and personal skills. It is therefore possible that the Unplugged curriculum, heavily relying on the development of social skills, was not able to deal with lack of self-esteem. Therefore, the effectiveness of this program after inclusion of gender-specific components warrants further formal evaluation.

A fourth alternative explanation for the observed difference could be a higher reliability of females in reporting risk behaviours, an interpretation which is not supported by previous findings. [25]

This study had both strengths and limitations. Main strengths are the large sample of students from diverse geographical locations, with enrolment and assessment conducted with a very standardized protocol. The survey instrument was administered individually and anonymously, thus ensuring high reliability of reports. The evaluation of effectiveness was performed through an experimental study design, with a good retention rate. The statistical analysis took into account the cluster effect, the hierarchical structure of the data and possible confounding factors. Main limitations were the low power of the study for subgroup analyses, which impacted on the precision of the estimates. Other limitations include the short-term follow-up, and possible bias due to self-reports of behavioural outcomes. This latter, however, should be of minor concern, since youths' answers in anonymous questionnaires appear generally highly reliable [26, 27] and not depending on gender. [25]

In conclusion, our findings suggest that school curricula based on comprehensive social influence against substance misuse may perform differently among girls and boys, possibly due to developmental and personality factors. Adding gender specific components to such programs and /or anticipating their delivery in early grades of the compulsory school could increase their overall effectiveness, but this possibility must be formally evaluated. 


\section{Acknowledgements}

Thanks to Prof. Dario Gregori for the critical advice in the statistical analysis, to Gian Luca Cuomo and Maria Paola Caria for the collaboration in the statistical analysis, and to Barbara Zunino for the administrative managing of the project. The following persons are acknowledged for their contribution to the field work and data collection: Samuela Bighiani, Alessandro Lanszweert, Paride Angius, Domenico Bernardi, Flavio Colacito, Rossella Gigante, Stefania Passerini and Laura Vitale, Italy; Regina Fenk, Elke Lantschik, Alexander Bohrn and Margot Koller, who also contributed to the design of the intervention program, Austria; Ann-Marie Lindahl and Renée Stockling, Sweden; Maria Kyriakidou, Greece.

\section{Competing interests}

None declared.

\section{Funding}

EU-Dap is a project funded by the European Commission (European Public Health program 2002 grant \# SPC 2002376). Additional national funding was provided by: Compagnia di San Paolo (grant \# 2002-0703) and Lega Italiana per la Lotta contro i Tumori (grant \# 2003 43/4) for the Novara centre, Swedish Council for Working Life and Social Research (grant \# 2002-0979) and Stockholm County Council (Public Health grant \# LS 0401-0117) for the Swedish centre.

\section{What this paper adds}

\section{What is already known on this subject}

The existing evidence on gender differences in the effectiveness of substance misuse preventive programs is rather mixed, with inconsistent results from a few studies presenting gender stratified analysis.

\section{What does this study add}

This paper presents evidence of a favourable effect of a comprehensive social influence programs among males, with lack of effect among females. The data suggested that age and psycho-social factors should be considered in order to enhance the program's effects among females. 


\section{References}

1. European Monitoring Centre for Drugs and Drug Addiction (EMCDDA). A gender perspective on drug use and responding to drug problems. Lisbon, November 2006

2. Stocco P, Llopis Llacer JJ, de Fazio L, Calafat A, Mendes F. Women drug abuse in Europe: gender identity. IREFREA 2000

3. Blake SM, Amaro H, Schwartz PM, Flinchbaugh LJ. A review of substance abuse prevention interventions for young adolescent girls. J Early Adolescence 2001; 21: 294-324.

4. Graham JW, Johnson CA, Hansen WB, Flay BR, Gee M. Drug use prevention programs, gender, and ethnicity: evaluation of three seventh-grade Project SMART cohorts. Prev Med 1990; 19: 305-313.

5. Longshore D, Ellickson PL, McCaffrey DF, St. Clair PA. School-based drug prevention among at-risk adolescents: effects of ALERT Plus. Health Educ Behav 2007; 34(4): 651-68.

6. Kulis S, Yabiku ST, Marsiglia FF, Nieri T, Crossman A. Differences by gender, ethnicity, and acculturation in the efficacy of the keepin' it REAL model prevention program. J Drug Education 2007; 37(2): 123-44.

7. Klepp KI, Tell GS, Vellar OD. Ten-year follow-up of the Oslo Youth Study Smoking Prevention Program. Prev Med 1993; 22(4): 453-462.

8. Vartiainen E, Paavola M, McAlister A, Puska P. Fifteen-year follow-up of smoking prevention effects in the North Karelia Youth Project. Am J Public Health 1998; 88(1): 81-85.

9. Sussman S, Sun P, McCuller WJ, Dent CW. Project Towards No Drug Abuse: two-year outcomes of a trial that compares health educator delivery to self-instruction. Prev Med 2003; 37: 155-162.

10. Perry CL, Komro KA, Veblen-Mortenson S, Bosma LM, Farbakhsh K, Munson KA, Stigler MH, Lytle LA. A randomized controlled trial of the middle and junior high school DARE and DARE Plus Programs. Arch Pediatr Adolesc Med 2003; 157: 178-184.

11. Shope JT, Kloska DD, Dielman TE, Maharg R. Longitudinal evaluation of an enhanced alcohol misuse prevention study (AMPS) curriculum for grades six-eight. J Sch Health 1994; 64(4):1606.

12. Faggiano F, Galanti MR, Bohrn K, Burkhart G, Vigna-Taglianti F, Cuomo L, Fabiani L, Panella M, Perez T, Siliquini R, van der Kreeft P, Vasara M, Wiborg G, and the EU-Dap Study Group. The effectiveness of a school-based substance abuse prevention program: EU-Dap Cluster Randomised Controlled Trial. Prev Med 2008 (Epub ahead of print)

13. Faggiano F, Richardson C, Bohrn K, Galanti MR, and the EU-Dap Study Group. A cluster randomized controlled trial of school-based prevention of tobacco, alcohol and drug use: the EU-Dap design and study population. Prev Med 2007; 44(2): 170-173.

14. van der Kreeft $P$, Wiborg G, Galanti MR, Siliquini R, Bohrn K, Scatigna M, Lindahl AM, Melero JC, Vassara M, Faggiano F, and the EU-DAP Study Group. "Unplugged": a new European school programme against substance abuse. Drugs: Education, Prevention and Policy (in press)

15. Scheier LM, Botvin GJ, Griffin KW. Preventive intervention effects on developmental progression in drug use: structural equation modeling analyses using longitudinal data. Prevention Science 2001; 2(2): 91-112.

16. Murray DM, Varnell SP, Blitstein JL. Design and analysis of group-randomized trials: a review of recent methodological developments. Am J Public Health 2004; 94(3): 423-32.

17. Rasbash J, Steele F, Browne W, Prosser B. A user's Guide to MLwiN, version 2.0. Centre for Multilevel Modelling. Institute of Education. University of London 2004.

18. Goldstein H. Multilevel Statistical Models. London, Edward Arnold, third ed., 2003. 
19. Bauer DJ, Preacher KJ, Gil KM. Conceptualizing and testing random indirect effects and moderated mediation in multilevel models: New Procedures and Recommendations. Psychol Methods 2006; 11(2): 142-163.

20. Amaro H, Blake SM, Schwartz PM, Flinchbaugh LJ. Developing theory-based substance abuse prevention programs for young adolescent girls. J Early Adolesc 2001; 21(3): 256-293.

21. Hess RS, Richards ML. Developmental and gender ingfluences on coping: implications for skills training. Psychol Schools 1999; 36(2): 149-157

22. Kumpfer KL, Smith $P$, Summerhays JF. A wakeup call to the prevention field: are prevention programs for substance use effective for girls? Subst Use Misuse 2008; 43(8): 978-1001.

23. Crump RL, Lillie-Blanton M, Anthony JC. The influence of self-esteem on smoking among African-American school children. J Drug Education 1997; 27: 277-291.

24. Sale E, Sambrano S, Springer FJ, Turner C. Risk, protection, and substance use in adolescents: a multi-site model. J Drug Education 2003; 33(1): 91-105.

25. Kandel DB, Schaffran C, Griesler PC, Hu MC, Davies M, Benowitz N. Salivary cotinine concentration versus self-reported cigarette smoking: Three patterns of inconsistency in adolescence. Nicotine Tob Res 2006; 8(4): 525-537.

26. Caraballo RS, Giovino GA, Pechacek TF. Self-reported cigarette smoking vs. serum cotinine among U.S. adolescents. Nicotine Tob Res 2004; 6(1): 19-25.

27. Post A, Gilljam H, Rosendahl I, Meurling L, Bremberg S, Galanti MR. Validity of self reports in a cohort of Swedish adolescent smokers and smokeless tobacco (snus) users. Tob Control 2005; 14(2): 114-7. 
Table 1. Main characteristics of the analytical sample at baseline, by gender and experimental group, the EU-Dap Study, October 2004.

\begin{tabular}{|c|c|c|c|c|c|c|c|c|}
\hline \multirow{3}{*}{ Characteristic } & \multicolumn{4}{|c|}{ Boys } & \multicolumn{4}{|c|}{ Girls } \\
\hline & \multicolumn{2}{|c|}{$\begin{array}{c}\text { Intervention } \\
\mathrm{n}=1695\end{array}$} & \multicolumn{2}{|c|}{$\begin{array}{l}\text { Control } \\
n=1629\end{array}$} & \multicolumn{2}{|c|}{$\begin{array}{c}\text { Intervention } \\
\mathrm{n}=1497\end{array}$} & \multicolumn{2}{|c|}{$\begin{array}{l}\text { Control } \\
n=1538\end{array}$} \\
\hline & $\mathbf{N}$ & Col\% & $\mathbf{N}$ & Col\% & $\mathbf{N}$ & Col\% & $\mathbf{N}$ & Col\% \\
\hline \multicolumn{9}{|l|}{ Centre } \\
\hline Spain & 85 & 5.0 & 106 & 6.5 & 298 & 19.9 & 452 & 29.4 \\
\hline Germany & 171 & 10.1 & 91 & 5.6 & 74 & 4.9 & 106 & 6.9 \\
\hline Belgium & 243 & 14.3 & 172 & 10.6 & 187 & 12.5 & 112 & 7.3 \\
\hline Stockholm & 274 & 16.2 & 212 & 13.0 & 104 & 6.9 & 115 & 7.5 \\
\hline Greece & 197 & 11.6 & 165 & 10.1 & 226 & 15.1 & 213 & 13.8 \\
\hline Austria & 156 & 9.2 & 214 & 13.1 & 170 & 11.4 & 156 & 10.1 \\
\hline Italy, centre 1 (Torino) & 335 & 19.8 & 407 & 25.0 & 127 & 8.5 & 216 & 14.0 \\
\hline Italy, centre 2 (Novara) & 88 & 5.2 & 167 & 10.3 & 181 & 12.1 & 41 & 2.7 \\
\hline Italy, centre 3 (L'Aquila) & 146 & 8.6 & 95 & 5.8 & 130 & 8.7 & 127 & 8.3 \\
\hline \multicolumn{9}{|l|}{ Age } \\
\hline $11-12$ years & 424 & 25.0 & 418 & 25.7 & 366 & 24.4 & 415 & 27.0 \\
\hline $13-18$ years & 1271 & 75.0 & 1211 & 74.3 & 1131 & 75.6 & 1123 & 73.0 \\
\hline \multicolumn{9}{|l|}{ Behaviours: smoking } \\
\hline Smoked cigarettes ever in life & 544 & 32.3 & 577 & 35.8 & 488 & 32.8 & 520 & 34.0 \\
\hline Smoked cigarettes - past 30 days & 157 & 9.8 & 246 & 15.7 & 238 & 16.5 & 227 & 15.2 \\
\hline Smoked $6+$ cigarettes - past 30 days & 91 & 5.7 & 154 & 9.9 & 131 & 9.1 & 136 & 9.1 \\
\hline Smoked $20+$ cigarettes - past 30 days & 60 & 3.7 & 100 & 6.4 & 81 & 5.6 & 86 & 5.8 \\
\hline \multicolumn{9}{|l|}{ Behaviours: drunkenness episodes * } \\
\hline Been drunk ever in life & 398 & 23.5 & 433 & 26.8 & 316 & 21.2 & 314 & 20.5 \\
\hline Been drunk - past 30 days & 93 & 5.6 & 118 & 7.4 & 75 & 5.1 & 87 & 5.7 \\
\hline Been drunk $3+$ times - past 30 days & 28 & 1.7 & 34 & 2.1 & 19 & 1.3 & 27 & 1.8 \\
\hline \multicolumn{9}{|l|}{ Behaviours: cannabis use * } \\
\hline Used cannabis ever in life & 123 & 7.3 & 169 & 10.5 & 90 & 6.0 & 88 & 5.7 \\
\hline Used cannabis - past 30 days & 51 & 3.0 & 86 & 5.4 & 36 & 2.4 & 36 & 2.4 \\
\hline Used cannabis $3+$ times past 30 days & 28 & 1.7 & 53 & 3.3 & 22 & 1.5 & 16 & 1.0 \\
\hline \multicolumn{9}{|l|}{ Behaviours: illicit drugs use *o } \\
\hline Used any illicit drug ${ }^{\circ}$ ever in life & 162 & 9.6 & 204 & 12.6 & 126 & 8.4 & 142 & 9.2 \\
\hline Used any illicit drug ${ }^{\circ}$ - past 30 days & 75 & 4.4 & 111 & 6.9 & 53 & 3.5 & 71 & 4.6 \\
\hline \multicolumn{9}{|l|}{ Score on positive self-esteem * } \\
\hline High (4-5) & 1394 & 87.0 & 1347 & 88.4 & 1185 & 82.7 & 1237 & 83.8 \\
\hline Low $(0-3)$ & 208 & 13.0 & 177 & 11.6 & 248 & 17.3 & 240 & 16.2 \\
\hline \multicolumn{9}{|l|}{ Positive expectations towards *: } \\
\hline Smoking: Feel relaxed & 426 & 26.3 & 435 & 28.0 & 398 & 27.3 & 392 & 26.4 \\
\hline Smoking: Become more popular & 343 & 21.2 & 331 & 21.2 & 262 & 17.9 & 312 & 20.9 \\
\hline Alcohol: Feel relaxed & 334 & 20.5 & 346 & 22.0 & 299 & 20.5 & 249 & 16.7 \\
\hline Alcohol: Become more popular & 279 & 17.2 & 273 & 17.4 & 216 & 14.8 & 217 & 14.5 \\
\hline Cannabis: Feel relaxed & 650 & 39.6 & 695 & 44.1 & 567 & 38.8 & 541 & 36.2 \\
\hline Cannabis: Become more popular & 339 & 20.7 & 350 & 22.2 & 266 & 18.1 & 286 & 19.1 \\
\hline
\end{tabular}

* proportions calculated out of number of subjects answering the question

- included: cannabis, tranquillizers, LSD, amphetamines, crack, cocaine, heroin, ecstasy, GHB, methadone, hallucinogens, ketamine. 
Table 2. Adjusted Prevalence Odds Ratios (POR) and 95\% Confidence Interval (CI) of substance use in the past $\mathbf{3 0}$ days among boys and girls, the EU-Dap Study short-term follow-up, May 2005.

\begin{tabular}{|c|c|c|c|c|c|c|}
\hline \multirow[b]{2}{*}{ Indicator of use } & \multicolumn{3}{|c|}{ Boys } & \multicolumn{3}{|c|}{ Girls } \\
\hline & $\begin{array}{l}\mathbf{n} / \mathbf{N}^{*} \\
\text { Cntr }\end{array}$ & $\begin{array}{c}\mathrm{n} / \mathbf{N}^{*} \\
\text { Int }\end{array}$ & Adj POR (95\%Cl) & $\begin{array}{l}\text { n/N } \mathbf{N}^{\star} \\
\text { Cntr }\end{array}$ & $\begin{array}{c}\mathbf{n} / \mathbf{N}^{*} \\
\text { Int }\end{array}$ & Adj POR $(95 \% \mathrm{Cl})$ \\
\hline Any smoking & $304 / 1509$ & $220 / 1563$ & $0.88(0.66-1.18)$ & $300 / 1453$ & $276 / 1412$ & $0.86(0.65-1.15)$ \\
\hline Frequent smoking & $211 / 1509$ & $126 / 1563$ & $0.68(0.50-0.93)$ & $175 / 1453$ & $171 / 1412$ & $1.07(0.74-1.55)$ \\
\hline Daily smoking & $159 / 1509$ & $80 / 1563$ & $0.49(0.34-0.71)$ & $117 / 1453$ & $113 / 1412$ & $0.99(0.64-1.52)$ \\
\hline Any drunkenness & $209 / 1548$ & $136 / 1623$ & $0.64(0.49-0.85)$ & $143 / 1501$ & $117 / 1456$ & $0.86(0.63-1.18)$ \\
\hline $\begin{array}{l}\text { Frequent } \\
\text { drunkenness }\end{array}$ & $80 / 1548$ & $51 / 1623$ & $0.68(0.45-1.04)$ & $39 / 1501$ & $25 / 1456$ & $0.66(0.37-1.18)$ \\
\hline Any cannabis & $161 / 1596$ & $88 / 1668$ & $0.62(0.45-0.85)$ & $63 / 1528$ & $64 / 1478$ & $1.05(0.70-1.58)$ \\
\hline Frequent cannabis & $106 / 1596$ & $54 / 1668$ & $0.60(0.40-0.91)$ & $30 / 1528$ & $34 / 1478$ & $1.17(0.59-2.33)$ \\
\hline Any illicit drug & $194 / 1615$ & $115 / 1686$ & $0.64(0.48-0.86)$ & $97 / 1534$ & $107 / 1495$ & $1.40(0.95-2.04)$ \\
\hline
\end{tabular}

* number of users out of the total number of students answering the question at follow-up (multilevel adjusted model).

POR, Prevalence Odds Ratios (intervention vs control) estimated using multilevel model 3 (RIGLS bin 1st order MQL with 3 levels, adjusted for centre prevalence of daily smoking and baseline use of the corresponding substance. 
Table 3. Transitions in substance use between baseline and follow-up in the EU-Dap Study, October 2004 - May 2005: boys.

\begin{tabular}{|c|c|c|c|c|c|c|c|c|}
\hline \multirow[t]{2}{*}{$\begin{array}{l}\text { Baseline use during } \\
\text { the past } 30 \text { days }\end{array}$} & \multicolumn{4}{|c|}{$\begin{array}{c}\text { Transition at follow-up (\%) } \\
\text { Intervention group }\end{array}$} & \multicolumn{4}{|c|}{$\begin{array}{c}\text { Transition at follow-up (\%) } \\
\text { Control group }\end{array}$} \\
\hline & $\mathbf{N}$ & Stable & Regressed $^{\circ}$ & Progressed $^{\#}$ & $\mathbf{N}$ & Stable & Regressed $^{\circ}$ & Progressed $^{\#}$ \\
\hline $\begin{array}{l}\text { Non smoker } \\
\text { (no cigarette } \\
\text { smoking) }\end{array}$ & 1410 & 91.7 & -- & 8.3 & 1274 & 90.2 & -- & 9.8 \\
\hline $\begin{array}{l}\text { Occasional smoker } \\
\text { (1-19 cigarettes) }\end{array}$ & 94 & 37.2 & 46.8 & 16.0 & 137 & 36.5 & 35.0 & 28.5 \\
\hline $\begin{array}{l}\text { Daily smoker } \\
\text { (20+ cigarettes) }\end{array}$ & 59 & 83.0 & 17.0 & -- & 98 & 81.6 & 18.4 & -- \\
\hline No drunkenness & 1531 & 94.1 & -- & 5.9 & 1436 & 90.3 & -- & 9.7 \\
\hline Drunkenness & 92 & 50.0 & 50.0 & -- & 112 & 62.5 & 37.5 & -- \\
\hline No cannabis use & 1620 & 96.5 & -- & 3.5 & 1511 & 93.8 & -- & 6.2 \\
\hline Cannabis use & 48 & 66.7 & 33.3 & -- & 85 & 78.8 & 21.2 & -- \\
\hline
\end{tabular}

* mutually exclusive categories of use

lower frequency of use reported at follow-up compared to baseline

\# higher frequency of use reported at follow-up compared to baseline

Table 4. Transitions in substance use between baseline and follow-up in the EU-Dap Study, October 2004 - May 2005: girls.

\begin{tabular}{|c|c|c|c|c|c|c|c|c|}
\hline \multirow{2}{*}{$\begin{array}{l}\text { Baseline use during } \\
\text { the past } 30 \text { days }{ }^{\star}\end{array}$} & \multicolumn{4}{|c|}{$\begin{array}{l}\text { Transition at follow-up (\%) } \\
\text { Intervention group }\end{array}$} & \multicolumn{4}{|c|}{$\begin{array}{c}\text { Transition at follow-up (\%) } \\
\text { Control group }\end{array}$} \\
\hline & $\mathbf{N}$ & Stable & Regressed $^{\circ}$ & Progressed $^{\#}$ & $\mathbf{N}$ & Stable & Regressed $^{\circ}$ & Progressed \\
\hline $\begin{array}{l}\text { Non smoker } \\
\text { (no cigarette } \\
\text { smoking) }\end{array}$ & 1183 & 91.0 & -- & 9.0 & 1237 & 90.1 & -- & 9.9 \\
\hline $\begin{array}{l}\text { Occasional smoker } \\
\text { (1-19 cigarettes) }\end{array}$ & 151 & 47.7 & 37.1 & 15.2 & 133 & 50.4 & 24.8 & 24.8 \\
\hline $\begin{array}{l}\text { Daily smoker } \\
\text { (20+ cigarettes) }\end{array}$ & 78 & 87.2 & 12.8 & -- & 83 & 81.9 & 18.1 & -- \\
\hline No drunkenness & 1385 & 93.9 & -- & 6.1 & 1417 & 93.4 & -- & 6.6 \\
\hline Drunkenness & 71 & 46.5 & 53.5 & -- & 84 & 58.3 & 41.7 & -- \\
\hline No cannabis use & 1442 & 97.4 & -- & 2.6 & 1492 & 97.4 & -- & 2.6 \\
\hline Cannabis use & 36 & 75.0 & 25.0 & -- & 36 & 69.4 & 30.6 & -- \\
\hline
\end{tabular}

${ }_{0}^{*}$ mutually exclusive categories of use

lower frequency of use reported at follow-up compared to baseline

" higher frequency of use reported at follow-up compared to baseline 
Table 5. Adjusted Prevalence Odds Ratios (POR) ${ }^{\circ}$ and $95 \%$ Confidence Interval (CI) of substance use in the past $\mathbf{3 0}$ days among boys and girls, by level of self-esteem, the EUDap Study short-term follow-up, May 2005.

\begin{tabular}{l|cc|cc}
\hline \multirow{4}{*}{ Indicator of use } & \multicolumn{2}{|c|}{ Boys } & \multicolumn{2}{c}{ Girls } \\
\cline { 2 - 5 } & $\begin{array}{c}\text { High self-esteem } \\
\mathbf{N = 2 7 4 1}\end{array}$ & $\begin{array}{c}\text { Low self-esteem } \\
\mathbf{N = 3 8 5}\end{array}$ & $\begin{array}{c}\text { High self-esteem } \\
\mathbf{N = 2 4 2 2}\end{array}$ & $\begin{array}{c}\text { Low self-esteem } \\
\mathbf{N = 4 8 8}\end{array}$ \\
\cline { 2 - 5 } & Adj POR (95\%Cl) & Adj POR (95\%Cl) & Adj POR (95\%Cl) & Adj POR (95\%Cl) \\
\hline Any smoking & $0.76(0.55-1.04)$ & $1.23(0.61-2.50)$ & $0.85(0.62-1.16)$ & $0.70(0.39-1.26)$ \\
Frequent smoking & $0.62(0.45-0.87)$ & $0.70(0.27-1.80)$ & $1.04(0.69-1.57)$ & $0.92(0.43-1.97)$ \\
Daily smoking & $0.46(0.30-0.68)$ & $0.56(0.20-1.58)$ & $0.86(0.53-1.40)$ & $1.35(0.63-2.87)$ \\
Any drunkenness & $0.69(0.50-0.94)$ & $0.58(0.29-1.17)$ & $0.83(0.58-1.19)$ & $1.23(0.66-2.29)$ \\
Frequent drunkenness & $0.71(0.43-1.14)$ & $0.75(0.25-2.19)$ & $0.59(0.31-1.12)$ & $1.71(0.49-5.92)$ \\
Any cannabis & $0.63(0.43-0.91)$ & $0.43(0.20-0.92)$ & $0.89(0.58-1.37)$ & $1.83(0.66-5.06)$ \\
Frequent cannabis & $0.62(0.39-1.00)$ & $0.42(0.16-1.09)$ & $0.74(0.38-1.43)$ & $2.14(0.58-7.95)$ \\
Any illicit drug & $0.68(0.48-0.97)$ & $0.35(0.18-0.71)$ & $1.27(0.88-1.85)$ & $1.59(0.78-3.22)$ \\
\hline
\end{tabular}

POR, Prevalence Odds Ratios (intervention vs control) estimated using multilevel model 3 (RIGLS bin 1st order MQL with 3 levels, adjusted for centre prevalence of daily smoking and baseline use of the corresponding substance.

Table 6. Adjusted Prevalence Odds Ratios (POR) ${ }^{\circ}$ and $95 \%$ Confidence Interval (CI) of substance use in the past 30 days among boys and girls, by age, the EU-Dap Study shortterm follow-up, May 2005.

\begin{tabular}{l|cc|cc}
\hline \multirow{4}{*}{ Indicator of use } & \multicolumn{2}{|c|}{ Boys } & \multicolumn{2}{c}{ Girls } \\
\cline { 2 - 5 } & $\begin{array}{c}\mathbf{1 1 - 1 2} \text { years } \\
\mathbf{N = 8 4 2}\end{array}$ & $\begin{array}{c}\mathbf{1 3 - 1 8} \text { years } \\
\mathbf{N = 2 4 8 2}\end{array}$ & $\begin{array}{c}\mathbf{1 1 - 1 2} \text { years } \\
\mathbf{N = 7 8 1}\end{array}$ & $\begin{array}{c}\mathbf{1 3 - 1 8} \text { years } \\
\mathbf{N = 2 2 5 4}\end{array}$ \\
\cline { 2 - 5 } & Adj POR (95\%Cl) & Adj POR (95\%Cl) & Adj POR (95\%Cl) & Adj POR (95\%Cl) \\
\hline Any smoking & $1.27(0.57-2.85)$ & $0.81(0.59-1.10)$ & $0.78(0.45-1.34)$ & $0.84(0.63-1.13)$ \\
Frequent smoking & $1.17(0.40-3.46)$ & $0.63(0.45-0.87)$ & $0.52(0.23-1.21)$ & $1.21(0.83-1.77)$ \\
Daily smoking & $1.41(0.35-5.75)$ & $0.41(0.28-0.61)$ & $0.45(0.18-1.13)$ & $1.19(0.77-1.85)$ \\
Any drunkenness & $0.56(0.25-1.28)$ & $0.63(0.48-0.83)$ & $0.44(0.19-1.04)$ & $0.94(0.68-1.29)$ \\
Frequent drunkenness & $0.53(0.13-2.24)$ & $0.69(0.46-1.04)$ & $0.70(0.16-3.01)$ & $0.65(0.37-1.16)$ \\
Any cannabis & $0.60(0.16-2.31)$ & $0.61(0.44-0.86)$ & $\S$ & $1.15(0.77-1.71)$ \\
Frequent cannabis & $\S$ & $0.62(0.40-0.95)$ & $\S$ & $1.19(0.62-2.27)$ \\
Any illicit drug & $0.90(0.36-2.23)$ & $0.61(0.45-0.83)$ & $1.03(0.47-2.28)$ & $1.42(0.98-2.06)$ \\
\hline
\end{tabular}

$\S$ the model did not converge because of the low number of observations

POR, Prevalence Odds Ratios (intervention vs control) estimated using multilevel model 3 (RIGLS bin 1st order MQL with 3 levels, adjusted for centre prevalence of daily smoking and baseline use of the corresponding substance. 